\title{
La influencia del campo social pro-bicicleta en el proceso de promoción del ciclismo urbano en Sevilla
}

\author{
The influence of the pro bicycle social field in the process of urban \\ cycling promotion in Seville
}

\author{
Pedro Malpica ${ }^{1}$ \\ Fecha de recepción: 09-02-2020 - Fecha de aceptación: 23-07-2020 \\ Hábitat y Sociedad (ISSN 2173-125X), n. ${ }^{\circ} 13$, noviembre de 2020, pp. 151-168. \\ http://dx.doi.org/10.12795/HabitatySociedad.2020.i13.09
}

\section{Summary}

In the successful process of planning, design and implementation of cycling infrastructures in Seville, the intervention and participation of certain actors proved to be decisive. In order to identify and characterize the evolution, milestones, components, interests and other relevant aspects of this process of cultural production, various qualitative and ethnographic techniques have been used, especially the interview, the participant observation and the analysis of sources, using Bourdieu's concept of field as a methodological axis according to Martín's proposal. Through the historical analysis of this local social field of urban cycling —-formed by technicians, politicians, institutions, firms and academics around a pre-existing core of activist kind- it can be stated that the specific knowledge held by its members, as well as their positions in different fields of influence, turned out to be decisive for such a proposal from municipal institutions to be well valued and embodied by broad social segments.

\section{Key words}

Urban cycling; Infrastructure; Social field; Habitat production and management; Social movements

\section{Resumen}

La intervención y participación de determinados agentes en el proceso de planificación, diseño y ejecución de las infraestructuras ciclistas en Sevilla redundaron de forma decisoria en el éxito de las mismas. Con el objeto de identificar y caracterizar la evolución, los hitos, los componentes, los intereses y otros aspectos relevantes de dicho proceso de producción cultural se ha acudido a diversas técnicas cualitativas y etnográficas, en especial la entrevista, la observación participante y el análisis de fuentes, utilizando el concepto de campo de Bourdieu como eje metodológico según la propuesta de Martín. Mediante el análisis histórico de este campo social local del ciclismo urbano -formado por personas técnicas, académicas y políticas, instituciones y empresas en torno a un núcleo preexistente de carácter activista- puede concluirse que los saberes específicos que ostentaban sus miembros, así como sus posiciones en distintos ámbitos de influencia, fueron determinantes para que la oferta de las instituciones municipales fuese bien valorada e incorporada por parte de amplios sectores sociales.

\section{Palabras clave}

Ciclismo urbano; Infraestructuras; Campo social; Producción y Gestión del Hábitat; Movimientos sociales 


\section{Introducción}

La dotación de infraestructuras ciclistas es, sin duda, un factor influyente en la promoción de la bicicleta como transporte urbano. La implantación de las mismas suele ser resultado de un proceso experimentado en ciertos ámbitos de decisión e influencia (administrativos, asociativos, empresariales...) desde donde se oferta el nuevo servicio, que se inserta entre las alternativas de movilidad disponibles. La implementación de las dotaciones y políticas de promoción del ciclismo urbano en Sevilla, condensadas especialmente en la red de carrilesbici construida a mitad de la pasada década, fue fruto de la iniciativa de un grupo de personas, relacionadas de formas diversas con el ciclismo urbano, que se articularon en torno a un núcleo pre-existente de carácter activista.

Los logros alcanzados mediante dichas políticas urbanísticas en pro del ciclismo urbano guardan estrecha relación con las características y evolución del grupo promotor que las desarrolló, con cuyo estudio intentaremos comprender de forma más completa las causas del éxito del "caso de Sevilla" e identificar claves que resulten útiles para procesos similares que se desarrollen en el futuro. Específicamente, el presente análisis histórico del proceso de promoción del ciclismo urbano en dicha ciudad se sirve de la propuesta de Martín (2008) sobre el campo social como herramienta metodológica, basada a su vez en el concepto de campo de Bourdieu y su importancia en los procesos de producción cultural.

\section{La pugna en la definición del espacio urbano}

Una de las grandes contribuciones a la sociología urbana de Lefebvre es el reconocimiento de la función de los individuos en la definición de la ciudad en contraposición al urbanismo diseñado por las élites. Los individuos y sus prácticas forman parte sustancial del proceso de urbanización y suponen un factor de resistencia frente a la planificación impersonal y alienante de las élites (cfr. Lefebvre, 1978; 1983). Lo urbano, por tanto, también es producido por los individuos en su práctica diaria, al relacionarse no solo en el espacio, sino con él. Por mucho que las instituciones públicas y el mercado intervengan sobre él de forma decisiva, los individuos lo habitan y hacen del mismo un uso cotidiano que difiere de la concepción previa de instituciones y empresas. En la producción social del espacio, las decisiones del Estado y del Mercado no suponen nunca un límite infranqueable para quienes lo habitan, sino un ámbito de disputa. De hecho, el interés por lo urbano y la disposición a intervenir en lo urbano es más propio de los individuos en situación de exclusión: "Lo urbano obsesiona a los que viven en la carencia, en la pobreza (...), la integración y la participación obsesionan a los no participantes, a los no integrados" (Lefebvre, 1978, p. 119). No serán las políticas de integración emanadas desde las instituciones públicas las que faciliten ese proceso, sino la auto-organización de los individuos que componen la sociedad urbana, aliados con aquella ciencia social que sea capaz de escapar del marco definido por el poder. La autogestión generalizada es para Lefebvre la práctica política idónea con la que la ciudad logrará ser producida de modo que cubra las necesidades de quienes la habitan: "solo la fuerza social capaz de investirse a sí mismo (sic) en lo urbano, en el curso de una larga experiencia políti- 
ca, puede asumir la realización del programa que imbrica a la sociedad urbana" (ob. cit., p. 136).

Como el espacio social, el sistema de transporte urbano también está producido en primera instancia por las élites, está caracterizado del mismo modo por la segregación, y se ve sometido igualmente a los fines de funcionalidad, productividad y mercantilización. Lefebvre, por todo ello, alerta de la necesidad de limitar la preeminencia del coche y aboga por el fomento de otras movilidades: "Muy pronto será necesario limitar, no sin dificultades y estragos, los derechos y poderes del auto" (Lefebvre, 1983, pp. 24-25), siendo preciso sustituirlo "por otras técnicas, otros objetos, otros medios de transporte" (Lefebvre, 1978, p. 151).

Basado en la matriz lefebvriana, el enfoque socioespacial de Gottdiener y Hutchison (2011) promueve el estudio de la dimensión política del plan urbanístico, su efecto en la fisionomía de la ciudad y en la conducta de su población, y analiza la alteración que, mediante el uso, los habitantes realicen del producto urbanístico. Al acuñar el concepto de red de crecimiento, Gottdiener expresa el sistema de alianzas cambiantes de personas y entidades diversas que confluyen en torno a una iniciativa de desarrollo urbano el cual, sin embargo, se enmarca exclusivamente en procesos de inversión urbanística y de obras públicas destinados a la búsqueda de beneficio económico en los que los principales intereses en juego son los del capital financiero y empresarial con la alianza del sector público (cfr. ob. cit., p. 92). En esta línea, es destacable la aparición de una escuela de "nuevo urbanismo" por parte de arquitectos y planificadores urbanos que propugnan un diseño y planificación de la ciudad que se apoye en procesos participativos y priorizan la recuperación de espacios peatonales y de transportes no contaminantes en lugar de espacios destinados al tránsito de automóviles (cfr. ob. cit., pp. 330-331).

Pero mientras que para humanizar la ciudad Gottdiener y Hutchison confían en una ruptura por parte de las vanguardias urbanísticas, y, aún antes, Lefebvre ponía sus esperanzas en la "ciencia de la realidad política (urbana)" y en unos hipotéticos procesos de auto-organización social (siempre aludidos de forma abstracta), Castells señala específicamente la función política desempeñada por los movimientos sociales en la configuración de lo urbano, en tanto que inciden en los servicios municipales y en el curso de las políticas locales (cfr. Castells, 1988, p. 310). Los movimientos sociales urbanos se convierten en "actores sociales al entregarse a una movilización en pro de una meta urbana que, a su vez, está ligada a la lucha general por la continua reestructuración de la sociedad" (Castells, 1986, p. 431). Al profundizar en la interrelación de los movimientos sociales y las instituciones municipales, Castells considerará la ciudad como producto de una pugna en torno a intereses diversos que terminarán por implantar un significado urbano de uno u otro tipo. Esta pugna se extiende a la reivindicación del acceso de la población a los bienes y servicios de consumo colectivo - como el transporte- que son asumidos por el sector público: su gestión tendrá desde las instituciones una concepción unidireccional y mercantilista si no se les contrapone desde los movimientos sociales una lógica basada en el valor de uso. Asimismo, estas demandas se deciden de forma autogestionada y participativa, frente al modelo de decisión autoritaria y centralizada impuesto desde las instituciones (cfr. ob. cit., pp. 432-438).

Pero Castells, sin negar la contribución de los movimientos sociales en una nueva configuración de la ciudad, considera que difícilmente 
tendrán capacidad de transformarla: "los movimientos sociales son incapaces de realizar plenamente su proyecto, ya que pierden su identidad en cuanto se institucionalizan" (ob. cit., p. 444) y vincula su verdadera función a un papel de resistencia ante las imposiciones de la clase dominante. Sin embargo, señala que los movimientos sociales sí tendrán capacidad de transformar la ciudad si consiguen imponer "un nuevo significado urbano en contradicción con el significado urbano institucionalizado y contra los intereses de la clase dominante" (ob. cit., p. 409). Para poder llevar a cabo el resto de sus demandas con éxito, los movimientos sociales no deberán actuar por sí solos, sino establecer sinergias con otros "operadores", tales como especialistas o partidos, desde cuyos ámbitos de decisión se canalicen sus propuestas en torno a la ciudad. En suma, y como única garantía de influencia real en la gestión y el diseño urbano, parece invitar a los movimientos sociales a "infiltrarse" en los espacios de decisión a través de aquellos ámbitos a los que más fácilmente pueden acceder, como el técnico o el político. $\mathrm{Y}$ a este respecto, el proceso que nos disponemos a analizar supone un excelente ejemplo del acierto de Castells al aconsejar tal extremo a los movimientos sociales.

El ciclismo urbano ha de enmarcarse como una forma de movilidad que participa en la redefinición humanizante de la ciudad: desde Lefebvre, habremos de considerarlo un transporte que, en ausencia de infraestructuras específicas, es desregulado y que por tanto reinterpreta en sus prácticas el espacio urbano mediante el uso proscrito de las vías y la transgresión de las normas de tránsito (definidas según los intereses del automóvil), y cuya promoción, realizada desde posiciones de exclusión y a través de procesos políticos basados en la auto-organización, merma los excesos y privilegios del tráfico motorizado; desde Gottdiener, veríamos las dotaciones ciclistas como un elemento distintivo de las propuestas de un nuevo urbanismo consciente y sensible con las necesidades de la ciudadanía y la salubridad ambiental del hábitat, oponiendo modelos alternativos a los principios mercantiles y administrativos de crecimiento emanados de las élites; desde Castells, subrayemos que las infraestructuras ciclistas suponen una reivindicación tradicional de los movimientos sociales urbanos con base al valor de uso de la ciudad. Los cambios acontecidos a mitad de la pasada década en Sevilla en materia de ciclismo urbano supusieron la oferta a la ciudadanía no solo de una nueva forma de locomoción, sino de un nuevo modelo de ciudad.

\section{El análisis del campo ciclista local como eje metodológico}

Si bien el concepto bourdieuano de campo en tanto que sistema específico de posiciones se circunscribía en su concepción inicial al estudio de la producción cultural, resulta también aplicable a procesos de producción de diverso tipo; es por tanto aplicable a ámbitos diversos y admite una gran heterogeneidad (cfr. Bourdieu, 1993, pp. 58- 59). El concepto de campo como herramienta metodológica permite el análisis de ciertos ámbitos de relaciones sociales "sin reducirlos a funciones generales o a instrumentos de una clase dominante" (Martín, 2008, p. 18). También evita los "saltos" especulativos que encontramos en algunos estudios en los que se vincula un hecho social determinado a grandes tendencias generales: es preciso analizar la red de relaciones 
"próximas" de los promotores y productores de un determinado bien o servicio, y su incidencia en el fenómeno que constituye el objeto de estudio; las transformaciones sociales de carácter general solo se consideran en tanto que puedan intervenir en dichas relaciones (cfr. ob. cit., p. 27-28).

En el campo social reside un capital específico, cuya apropiación sus componentes se disputan en función de los distintos intereses y posiciones de sus miembros; esta contienda redefine el campo confiriéndole un carácter dinámico. Existe asimismo una jerarquía entre sus componentes en función de la distribución del capital común —esto es, según el capital que se alcanza en cada posición-. El campo se caracteriza por un tipo de creencia que le es específica y por ostentar una autonomía relativa resultante de un proceso de autonomización y que es directamente proporcional a la revalorización simbólica de sus especialistas. Los saberes propios del campo le dotarán de mayor autonomía si se convierte en "punto de paso obligado" para cualquier actor externo interesado en el ámbito de especialización. Junto al análisis de las relaciones próximas es importante también el estudio de las alianzas externas del campo y sus efectos en otros campos; el campo habrá de reaccionar ante poderes externos, que, a su vez, propician la aparición de disputas internas en el campo. Se hace preciso así abordar el análisis del proceso y evolución del campo, su autonomización y su articulación externa. La aplicación de esta herramienta es consustancial a un análisis histórico de procesos (cfr. ob. cit., pp. 15-18, 23-25 y 30-31).

El campo puede ofrecer un producto específico y con ello ayuda a producir una determinada necesidad y a redefinir tanto el espacio de las prácticas preexistentes como el significado a ellas asociado, manteniendo una serie de intereses propios "que se definen en el espacio de competencia con otros productores", por lo que toman posiciones en un espacio delimitado desde una autonomía relativa, esto es, desde "dinámicas propias no reductibles a procesos sociales más generales" (ob. cit., p. 15). Finalmente la persona individualmente en función de su habitus decide adoptarla o no, permitiéndose así que dicha práctica pueda ser reinsertada en su sistema de gustos y preferencias (cfr. Bourdieu, 1993, p. 74; 1998, pp. 205-206). Una amplia aceptación repercute en el capital simbólico ostentado por el campo. Definir y caracterizar el campo nos permite, entre otras cosas, no solo conocer las circunstancias en las que se configuró el ámbito que rige la actividad, sino observar la génesis y definición social del fenómeno mismo, su posterior difusión y popularización, así como las rupturas culturales con modelos que le precedieron (cfr. Bourdieu, 1993, p. 60).

La interacción entre el campo y las instituciones, y la interdependencia entre ambos, es uno de los aspectos fundamentales de este tipo de análisis (cfr. Martín, 2008, pp. 19-22). Al analizar el campo, debemos considerar el ámbito asociativo y el institucional, así como las interrelaciones entre ambos, superando las limitaciones de algunos estudios sobre las iniciativas pro-bicicleta que se centran exclusivamente en la gestión institucional o que, por el contrario, vinculan casi exclusivamente su génesis a factores asociativos y participativos. Con tal fin, el campo bourdieuano resulta ser un concepto más abierto que otros, como la red de crecimiento de Gottdiener, a pesar de la gran utilidad de esta última en el análisis de la implementación de infraestructuras municipales. Dadas las características del proceso de implantación del carril-bici sevillano (en el que, si bien existe intervención empresarial, se centra en los ámbitos asociativo e institucional) el concepto de campo 
2 Se ha procedido al análisis de fuentes tales como artículos de prensa, programas de radio, foros de internet, páginas Web, folletos turísticos, productos audiovisuales, fotografías, publicaciones asociativas, publicidad, etc. de 2008 a 2019.

3 La muestra constó de diez entrevistas no-estructuradas, celebradas entre 2009 y 2011, a los siguientes perfiles: 1) Cargo relevante de la Gerencia Municipal de Urbanismo y del Plan Director de la Bicicleta de Sevilla. 2) Consultor en movilidad no contaminante para el Plan Director de la Bicicleta de Sevilla. 3) Técnica municipal de urbanismo. 4) Miembro relevante de la asociación A Contramano de Sevilla. 5) Activista en urbanismo social. 6) Administrador de una Web temática sobre ciclismo urbano en Sevilla. 7) Propietario de una tienda y taller de reparación de bicicletas. 8) Dependienta en una tienda y taller de reparación de bicicletas. 9) Bicimensajero y dependiente de una tienda de bicicletas. 10) Mecánico y propietario de un taller de reparación de bicicletas.

4 Muestra de 15 entrevistas semiestructuradas realizadas en 2009 y 2010 a ciclistas urbanos de Sevilla, de entre 21 y 55 años, de ambos sexos, de distintos perfiles socioprofesionales y diverso grado de experiencia al manillar.

5 Muestra estructural cualitativa de 12 grupos de discusión celebrados en 2014 en Sevilla y otras ciudades andaluzas, correspondientes a otras tantas posiciones sociales definidas por clase social, profesión, sexo, edad, nivel educativo y barrio de residencia; fue posible gracias a la subvención de la Consejería de Fomento y Vivienda de la Junta de Andalucía dentro de la convocatoria I+D+i de 2013-2014. resulta mucho más adecuado, siendo además más adaptable a un análisis centrado en un proceso de ámbito local; además, como se ha visto, es más operativo para el estudio de la aceptación ciudadana de las iniciativas municipales dada su relación con las estructuras disposicionales de los distintos perfiles sociales, aspecto muy aplicable a la incorporación de la propuesta ciclista por amplios sectores de la ciudadanía sevillana. Asimismo, y no menos importante, la caracterización del campo como ámbito dinámico en el que tienen lugar una serie de movimientos internos mediante los que se establece una disputa por el poder y una cambiante toma de posiciones (cfr. Martín, 2008, p. 30) nos permite analizar de forma más completa las posiciones dinámicas de liderazgo mantenidas por los diversos promotores de las nuevas políticas e infraestructuras ciclistas y, fundamentalmente, la influencia de sus actuaciones ante otros campos, sean adversos o aliados.

En el caso de nuestro estudio, el núcleo central de este conjunto de personas y entidades estaba establecido en Sevilla y su evolución tuvo un carácter marcadamente local, si bien en algunos casos incidieron de una u otra forma en el proceso entidades cuyo ámbito no se circunscribía al municipal: Gottdiener y Hutchison (2011, p. 14, 16, 88 y 91-92) inciden desde el enfoque socioespacial en la importancia de considerar la intervención de entidades externas al ámbito local en los procesos de urbanización y de obras públicas; también Martín (2008) indica que los campos raras veces se limitan a un espacio específico: "en muchos casos, sus dinámicas solo se comprenden en el seno de entramados interestatales" (p. 30). Aunque en nuestro análisis hayamos delimitado el alcance del "campo social" a una concepción local del mismo no obviaremos su más amplia expresión al contextualizar el análisis en el entramado de relaciones interterritoriales más extensas.

El presente análisis no es, ni ha pretendido ser, un estudio íntegro de las relaciones internas y externas que en él confluyen. Martín indica que, dada la multiplicidad de factores intervinientes en las relaciones, no se trata de realizar un estudio exhaustivo de los mismos y que la metodología relacional que ofrece el concepto de campo "no implica que en cada investigación sea preciso estudiar todas las relaciones de los entramados y toda su historia" sino que se debe "limitar, en cada caso concreto, el conjunto de relaciones a estudiar", seleccionando las dimensiones, fases y espacios específicos de la red que se consideren más pertinentes para la investigación, en tanto que "ninguna explicación podría agotar todo el conjunto de causas eficientes" (Martín, 2008, p. 31).

Para realizar el estudio del campo social del ciclismo urbano sevillano se ha recurrido al análisis bibliográfico y de fuentes documentales, ${ }^{2}$ a las entrevistas a informantes-clave ${ }^{3}$ y al método etnográfico, destacando en este la observación participante en los ámbitos académicos y asociativos del campo local ciclista. Con un alcance algo más limitado en relación a la especificidad de este estudio, se ha recabado adicionalmente información sobre el proceso según se han expresado en las entrevistas a usuarios y usuarias de bicicleta como modalidad de transporte ${ }^{4}$ y en los grupos de discusión ${ }^{5}$ según los puntos de vista y opiniones de los y las participantes. Dichas técnicas de investigación conformaron conjuntamente el trabajo de campo de la tesis doctoral del autor del presente artículo (Malpica, 2017). El estudio del campo local del ciclismo urbano ha sido en buena parte posible por haber iniciado muy tempranamente nuestra investigación en terreno, así como por el hecho de que el proceso se encuentra documentado de forma exhaustiva. 
Es preciso señalar que debido al compromiso de confidencialidad adquirido ante las personas entrevistadas y ante los y las informantes, las fuentes que nos disponemos a plasmar a continuación se expresarán de tal forma que no sean identificables.

\section{La evolución del campo local ciclista}

El proceso de implementación de las infraestructuras ciclistas en Sevilla fue propiciado por la confluencia en la esfera asociativa de una serie de personas provenientes de los ámbitos académico, empresarial, técnico y político, cuyas posiciones, intereses y responsabilidades, a su vez, se vieron afectadas por el propio proceso. El análisis de dicho grupo y de su relación con otras entidades es fundamental para entender la evolución de los acontecimientos que finalmente se concretaron en las infraestructuras y dotaciones existentes en la capital andaluza, así como en el consiguiente auge del ciclismo urbano en la ciudad.

La aparición de un incipiente campo local ciclista en Sevilla puede datarse en los años ochenta del siglo pasado. Por entonces se circunscribía a la asociación A Contramano, recién creada, y a los comercios de venta de bicicletas y accesorios ciclistas por entonces existentes (que en ese momento se dirigían prioritariamente a una clientela vinculada con el ciclismo recreativo), y apoyos puntuales en otros ámbitos asociativos, como el ecologista o el pacifista, y en clubes de ciclismo deportivo. Ha de subrayarse la función de liderazgo desempeñada en su seno por parte de la asociación A Contramano que, desde su aparición, muy anteriormente a la implementación de la red de carriles-bici, constituyó el eje vertebrador de dicho campo. Por entonces su influencia institucional, social y política era limitada, aunque, anticipándose al posterior alcance de los acontecimientos, combinó la defensa activista de los derechos de los ciclistas a pie de calle con una labor asimilable a la de consultoría de ciclismo urbano para los sucesivos gobiernos municipales. Esta doble práctica política supuso uno de los grandes potenciales de la asociación: "el respeto de las instituciones te lo ganas de las dos maneras", asegura un informante vinculado a A Contramano.

En su faceta activista, la labor reivindicativa de A Contramano tuvo desde finales de los años ochenta un considerable impacto en Sevilla y desempeñó una importante función de difusión y sensibilización de las necesidades de los y las ciclistas urbanos. La iniciativa de implantar una red de carriles-bici respondía a una antigua demanda de los ciclistas sevillanos. Desde los años ochenta, era habitual observar, atadas al cuadro de muchas de las bicicletas de las que por entonces se encontraban en circulación, las placas de plástico con la leyenda "Carril bici iya!", distribuidas por A Contramano como forma de reivindicación ciudadana en pro de la construcción de un carril-bici. Bajo ese mismo lema se convocaron muchas de las manifestaciones y marchas ciclistas que tuvieron lugar en Sevilla, celebradas al menos una vez al año desde 1989, destacando entre ellas la que logró la confluencia de 10000 personas en la marcha ciclista de 1993 (cfr. A Contramano, 2008, p. 4). A lo largo del tiempo, las movilizaciones ciclistas se mantuvieron con variable intensidad y acudiendo a nuevos formatos: en los años previos a la construcción de la actual red de carriles-bici — junto a las marchas ciclistas "clásicas", que se mantenían desde décadas atrás- apareció también un nuevo modelo de reivindicación de difusión internacional: la "Masa crítica" o "Bici crítica" iniciativa autogestionada, convocada informal- 
mente, y reproducida en Sevilla por un grupo de ciclistas (entre ellos, miembros de A Contramano). La frecuencia de este tipo de convocatoria en Sevilla llegó a ser en ciertos periodos mensual.

Paralelamente, en su faceta de consultoría, A Contramano mantuvo una regular interlocución con el Ayuntamiento de Sevilla y otras entidades, en los que contribuyó con información especializada y asesoramiento técnico, estableciendo relaciones de interdependencia con las instituciones públicas. En el ámbito local, mucho antes de la implementación de la actual red de carriles-bici sevillana, la asociación A Contramano ya había realizado propuestas al Ayuntamiento de Sevilla en diversas ocasiones: propusieron una red de carriles-bici por primera vez en 1990, al calor de las exitosas movilizaciones precedentes, antes aludidas; algunos aspectos de esta propuesta se incorporan al "Plan Especial de la Bicicleta" municipal de 1993. Desde entonces realizaron periódicamente sucesivas propuestas en materia de movilidad no contaminante ante las instituciones, las cuales en ocasiones se tradujeron en nuevas actuaciones municipales, aunque estas se caracterizaron por su alcance limitado y por no lograr la influencia social que supusieron las intervenciones posteriores a 2004 (cfr. A Contramano, 2008, pp. 7-8).

En los primeros pasos de consolidación de asociaciones de ciclismo urbano también se emprenden los primeros intentos de coordinación interterritorial. En la toma de contacto inicial y posterior conformación de una coordinación estatal de activistas a favor del ciclismo urbano (germen de ConBici, vid. infra.) fue clave la facilitación prestada por el partido Los Verdes; a su vez, tanto las organizaciones como la plataforma estatal que resultó de su coordinación mantuvieron su autonomía respecto a este y otros partidos políticos. En lo referente a la coordinación con asociaciones a favor del ciclismo urbano de otros ámbitos territoriales, A Contramano fue fortaleciendo sus vínculos a través de la coordinadora Andalucía por la Bici (a nivel andaluz), la coordinadora ConBici (a nivel estatal), la Federação Portuguesa de Cicloturismo e Utilizadores da Bicicleta (a nivel ibérico) y la European Cyclists' Federation (a nivel europeo), a menudo ostentando una actividad notable en los foros en los que participaba; la influencia de algunos de sus miembros, vinculados a la política o a la academia, dotaba al campo de mayor respetabilidad a pesar de su reducido tamaño. Asimismo, el intercambio de información, experiencias e ideas en estas plataformas interterritoriales —verdadero campo general del ciclismo urbano, con más sólidos vínculos con los ámbitos gubernamentales, empresariales, mediáticos o científicos cuanto mayor era su alcance geográfico-, y la proyección exterior que en ocasiones se tuvo en ellas, contribuyó a la acumulación de un mayor capital simbólico de la asociación A Contramano ante otros agentes locales.

Este intercambio de información fue un recurso muy fructífero que se plasmaría más adelante en algunas de las decisiones que se implementarían en Sevilla - la elección de carriles-bici segregados de dos sentidos fue inspirada en la infraestructura ya existente en ciudades como Donostia, y el modelo que sirvió de base para la normativa municipal ciclista fue el de la normativa de Barcelona, entre otros muchos ejemplos- y a su vez supondría posteriormente la consideración de la infraestructura ciclista sevillana como una "buena práctica" que mereció la atención de personas técnicas y políticas municipales de diversas ciudades del mundo (cfr. Marqués, 2011, p. 12). Muchos de los aciertos en el diseño de las dotaciones ciclistas sevillanas, como la continuidad y conectividad del carril-bici en todos los barrios, la seguridad y protec- 
ción de su trazado ante las amenazas del tráfico motorizado, la ubicación de las estaciones de bicicletas urbanas y de los aparcamientos para bicicletas, entre muchos otros, no pueden descontextualizarse de este intercambio de información y de aprendizaje en las redes interterritoriales especializadas en el ciclismo urbano.

Para la coordinación entre las entidades conformantes de estas redes asociativas, en especial las de mayor ámbito geográfico, fue imprescindible, junto a la celebración de encuentros presenciales periódicos, la coordinación postal, telefónica y telemática, resultando paulatinamente más ágil, fluida y continuada la interlocución entre ellas a medida que aparecían nuevas tecnologías de comunicación. Si bien en el ámbito andaluz, español e ibérico se estableció un calendario de encuentros presenciales relativamente fluido — más intenso y abierto, por motivos obvios, cuanto más reducido era el ámbito territorial de coordinación-; en el ámbito europeo los encuentros presenciales efectivos fueron más ocasionales y formales - y accesibles, por motivos prácticos, a un menor número de personas.

Es al calor del proceso de la planificación y de la posterior construcción del carril-bici cuando el campo ciclista sevillano creció, tuvo mayor influencia y se volvió más heterogéneo, incorporando a ediles, técnicos municipales y miembros de partidos políticos. La llegada de un nuevo gobierno consistorial tras el pacto entre el Partido Socialista Obrero Español (PSOE) e Izquierda Unida (IU) en 2003 propicia en los años inmediatamente posteriores la creación municipal de la Oficina de la Bicicleta y la aprobación del documento Bases y Estrategias para la Integración de la Bicicleta en la Movilidad Urbana de Sevilla, que recoge la construcción de la primera fase de la red de carriles-bici ("red básica”). Asimismo, el Ayuntamiento pone en marcha en 2004 los presupuestos participativos, que reeditará en 2005, año en el que la propuesta más votada es la implantación de un sistema de carriles-bici en la ciudad. La construcción de la primera fase de la red arranca en 2006 y aún está en ejecución en 2007, año en que se celebran nuevas elecciones municipales. El gobierno municipal resultante de las mismas, fruto de la reedición del pacto entre PSOE e IU, aprueba en su primer año de legislatura municipal el Plan Director para el fomento de la bicicleta en Sevilla, que reúne todas las medidas de promoción de la bicicleta que se venían poniendo en marcha durante los últimos años (vid. infra), institucionalizándolas y proyectándolas hacia el futuro. Dos años más tarde se pone en marcha la construcción de la segunda fase de la red de carriles-bici ("red complementaria"), y se vertebra a nivel estatal con otras instituciones municipales en la Red de Ciudades por la Bicicleta, fundada precisamente en Sevilla.

La conformación de la Oficina de la Bicicleta — con la que colaboraron profesionalmente algunos miembros de A Contramano- y la creación de la Comisión Cívica de la Bicicleta —en la que participaron A Contramano y otras entidades asociativas - supuso un proceso de institucionalización en las funciones que estos actores venían desempeñando en el campo. La creación de dichos foros y la repercusión de las resoluciones logradas a través de los presupuestos participativos allanaron la consolidación de vínculos con diversos activistas sociales -no solo ciclistas: también asociaciones ecologistas, de peatones y de patinadores-y expertos provenientes de la sociedad civil, consultorías medioambientales, páginas Web temáticas, investigadores, y otras personas y entidades. Estas nuevas incorporaciones se tradujeron en medidas concretas: por ejemplo, la inclusión de las movilidades de discapa- 
citados y patinadores en la normativa reguladora del uso del carril-bici se originó en este ámbito participativo.

A lo largo de este proceso, los activistas pro-bicicleta, que anteriormente habían mantenido cierto papel "promotor", o incluso "gestor", adoptan ahora una función formalmente legitimada pero circunscrita a la interlocución. Desde este momento, la centralidad del campo podría parecer recaer en el gobierno municipal, y, de hecho, la preponderancia de la esfera institucional supuso una recomposición evidente del campo y de sus liderazgos, así como la consideración de un nuevo conjunto de intereses (réditos electorales, equilibrio presupuestario, sensibilidad ante la opinión pública, etc.) que hasta entonces no habrían sido considerados tan importantes. Sin embargo, no ha de obviarse que muchas de las colaboraciones especializadas necesarias para el desarrollo de dicho plan fueron encargadas a miembros del ámbito asociativo, quienes de forma tanto profesional como voluntaria intervinieron decisivamente en la planificación, diseño, toma de decisiones y ejecución de las diversas actuaciones planteadas.

Más importante aún, algunos miembros de A Contramano pertenecían a su vez a uno de los partidos políticos que conformaban el gobierno municipal de coalición y alcanzaron responsabilidades políticas, técnicas y político-técnicas en el equipo municipal. Los miembros de A Contramano también formaban parte de otras entidades intervinientes en el proceso o mantenían estrechos vínculos con ellas, como consultorías, pequeños negocios, clubes deportivos o la propia universidad. Algunas de estas entidades - académicas, empresariales, etc.crecieron y se fortalecieron durante el proceso y cobraron una progresiva importancia e influencia. Dada esta ubicuidad de los miembros de A Contramano, incluyendo posiciones de decisión política, su labor resultó ser clave a la hora de integrar los diversos intereses políticos, técnicos, institucionales, económicos, académicos y asociativos que emanaban desde las distintas posiciones participantes. Se pueden describir por tanto las relaciones entre las distintas posiciones del campo durante el proceso - y en especial la relación entre las posiciones políticas y las asociativas - como fluidas y armónicas. De hecho, los únicos conflictos relevantes dentro del campo ciclista, una vez institucionalizado, tuvieron lugar en el seno del ámbito estrictamente consistorial del campo: concretamente, entre algunas posiciones políticas y algunas posiciones técnicas.

En tanto que algunas funciones políticas y técnico-políticas recaían en personas con experiencia en A Contramano y en el activismo pro-bicicleta - y estaban por tanto vinculadas al campo desde etapas anteriores a la fase de institucionalización-, en ellas se combinaba dicha experiencia asociativa con una trayectoria partidista: al tomar posesión de cargos electos o de puestos de decisión formal, dichas personas dotaron al proceso de determinados saberes propios del ámbito político, administrativo e institucional que se tradujeron en ciertas acciones necesarias para la evolución del proyecto, las cuales resultaron en ocasiones ser de crítica importancia. Ejemplo de ello fue el logro inmediato de financiación (unos 18 millones de euros para la construcción de la "red básica" o primera fase de implementación) a través de la "decisión estratégica", tal y como la llaman algunos entrevistados que formaron parte del proceso, consistente en su inclusión en el Plan General de Ordenación Urbana como "sistema general" (esto es, de importancia estructural en la ciudad) aprovechando la oportunidad que supuso la revisión de dicho Plan; ello supuso que la construcción del carril-bici, 
dado su carácter estructural, no podía ser soslayada ni aplazada, y a efectos presupuestarios y financieros, ello también supuso que se respondiera ante el área de Urbanismo del consistorio en lugar de rendir cuentas al área municipal de Movilidad (Tráfico), opuesta inicialmente al desarrollo de la movilidad ciclista y que con toda probabilidad, de haber podido, habría puesto numerosas objeciones al avance del proceso. También fue fruto de la aplicación de estos saberes "políticos" el firme mantenimiento, durante las negociaciones con el resto de los ámbitos institucionales, de las líneas de actuación previstas.

Pero posiblemente la aportación fundamental desde estas posiciones del campo fue la propia voluntad política: frente a actitudes más prudentes que en ocasiones se mantuvieron desde los perfiles netamente asociativos (como la propuesta de limitar inicialmente el alcance territorial del carril-bici para no generar alarma en los ámbitos más contrarios al proyecto), las posiciones técnico-políticas resultaron fundamentales para apostar por su aplicación íntegra. Así, uno de los elementos novedosos del caso de Sevilla y que constituyó uno de los motivos por los que se convirtió en referente internacional, como fue la ambiciosa implementación de todas las infraestructuras ciclistas en un corto plazo de tiempo, pudo materializarse precisamente por la determinación demostrada desde las posiciones que conjugaron disposiciones activistas con una capacidad decisoria de carácter político e institucional.

Asimismo, para la ejecución de la propia infraestructura se contó con la contribución de empresas constructoras, peritos y otros organismos del ámbito de la planificación urbana, tráfico y obras públicas; en este aspecto, y ante la ausencia de precedentes locales, fue necesario innovar conjuntamente desde la esfera institucional, empresarial y técnica en lo referente a la tecnología empleada y la producción de los insumos adecuados. La incorporación de ciertos servicios específicos, tales como el sistema de bicicletas públicas Sevici, el Sistema Integral de la Bicicletas de la Universidad de Sevilla (SIBUS) o el sistema de intermodalidad Bus+Bici, propiciaron la intervención de entidades como la empresa de publicidad JCDecaux, la Universidad de Sevilla o el Consorcio de Transporte Metropolitano, las cuales, si bien abarcaban ámbitos de actividad que difícilmente pueden circunscribirse al ciclismo urbano, desarrollaron por su implicación en el proceso intereses específicos en relación al mismo. El sector del pequeño comercio ciclista, adaptado al auge del ciclismo urbano y cada vez más numeroso, también engrosó el campo local.

Las disposiciones relativas al ya mencionado triple carácter ciclista, especialista y activista influyeron en muchas de las decisiones que se tomaron y ejecutaron, las cuales, finalmente se probaron como acertadas al obtener una respuesta positiva de amplios sectores de la población de la ciudad. En un estudio emprendido por el Ayuntamiento en la fase inicial del proyecto, se detectó que en Sevilla había unas 200000 bicicletas (de las cuales solo se utilizaban unas 6000) y que muchos de sus propietarios se plantearían utilizarla como vehículo en las condiciones de seguridad que ofreciera un carril-bici segregado. Basada en ello, se tomó la decisión de planificar las infraestructuras ciclistas no en función de la demanda existente, sino en función de la demanda potencial. En una entrevista a un mecánico de bicicletas, este describe cómo en los meses siguientes a la puesta en funcionamiento del carril-bici aparecían numerosos clientes que traían bicicletas de modelos antiguos, a veces deterioradas u oxidadas, para su puesta a punto: "las 
bicicletas de los trasteros, de la casa de veraneo, bicis que estaban hechas cisco" que tras mucho tiempo sin usarse sus dueños recuperaban y arreglaban para comenzar a desplazarse en bicicleta por la ciudad. Desde las primeras fases de implementación de las infraestructuras, estas se revelaban como un éxito, y los supuestos sobre los que el campo local del ciclismo urbano se basó a la hora de impulsar la iniciativa resultaron certeros.

En la fase de planificación, diseño y primera etapa de la construcción de los carriles-bici, una vez se constató que dicha iniciativa sería ejecutada, surgió una mayor resistencia a la misma por parte de determinados ámbitos municipales con intereses contrapuestos a los del campo ciclista (estos intereses guardarían relación, particularmente, con ciertas disposiciones pro-automóvil). Hasta entonces el proyecto no había generado grandes reticencias en dichos ámbitos en tanto que supusieron que, de manera similar a otras iniciativas emprendidas en el pasado, todo acabaría en un mero documento de un proyecto que nunca se implementaría ("un papel archivado en un cajón”, en palabras de un entrevistado); fue en el momento en el que se constató su efectiva implementación cuando aparecieron los obstáculos. En el plano institucional, este conflicto de intereses se evidenció en la relación del campo ciclista con ciertas entidades municipales, y especialmente con la Dirección de Movilidad (Tráfico) que mantenía en el Ayuntamiento intereses contrarios a los representados por el campo del ciclismo urbano y que rehusó la invitación de formar parte de los organismos de participación; asimismo, desde esta instancia se adujeron criterios técnicos referentes a la gestión del tráfico urbano para sustentar, en un primer momento, su negativa inicial a la propia ejecución global de la misma y, posteriormente (una vez que ya se llevaba a cabo la construcción del carril-bici), cuestionar el alcance que debía permitirse su implementación, condicionando que en la ejecución de la primera fase de la red de carriles-bici se respetara de forma estricta el espacio destinado a la circulación motorizada en la calzada y limitando los tipos de vehículos que podrían circular por el carril-bici, entre otros impedimentos.

Las tensiones entre estos agentes, que podemos simplificar como la contienda entre dos modelos incompatibles de movilidad - la motorizada y la no contaminante-, se enmarcaba en la "polémica local" surgida a raíz de las nuevas infraestructuras y dotaciones ciclistas, cuyo alcance rebasó el específico ámbito institucional: la disputa entre distintos intereses se expandió a todas las fuerzas vivas de la ciudad. El proceso, desde que se inició la implementación de las nuevas dotaciones, tuvo que afrontar diversos obstáculos provocados desde campos adversos a la promoción del ciclismo urbano, entre ellos una fuerte y hostil campaña mediática, así como diversas movilizaciones ciudadanas en contra de las nuevas infraestructuras y el inicio de procedimientos legales contra la ordenanza reguladora del tráfico ciclista y contra otras medidas municipales de promoción el ciclismo urbano, sin que finalmente todo ello afectara sustancialmente al éxito de las nuevas dotaciones.

La campaña hostil al carril-bici y la consecuente polémica local en torno al mismo supusieron un refuerzo de las posiciones contrarias al ciclismo urbano en el ámbito institucional, mientras que el propio éxito del carril-bici las debilitaba. Dicho éxito fue de tal magnitud que los objetivos del campo ciclista pudieron finalmente alcanzarse en su práctica totalidad. Esta pugna se refleja en las propias características de la infraestructura ciclista sevillana: las intrincadas negociaciones entre 
facciones llevaron inicialmente a una serie de consensos en virtud de los cuales las condiciones de ejecución de los carriles-bici se vieron dificultadas, sobre todo en lo referente a reasignar parte del espacio de la calzada a las nuevas dotaciones (así, buena parte de la "red básica" construida en la primera fase de ejecución afrontó limitaciones espaciales que pueden aún observarse en determinados aspectos del carrilbici, sobre todo en los elementos más criticados tanto por sus usuarios como por sus enemigos, tales como la estrechez de algunos de sus tramos, la contigüidad con aceras sin elementos de segregación, o la existencia de árboles o postes en la mediana del carril en algunos puntos del mismo). Sin embargo, una vez alcanzado un alto nivel de aceptación y de uso de la nueva infraestructura, los posteriores acuerdos logrados beneficiaron en mayor medida a los intereses de las posiciones a favor del ciclismo urbano, en tanto que el respaldo ciudadano a su estrategia les confirió de mayor legitimidad, y la jerarquización simbólica dentro de las instituciones municipales, presumiblemente, se modificó en favor de las posiciones del campo ciclista.

Esta nueva situación se observa en la más funcional factura de los carriles ejecutados en la segunda fase y en posteriores intervenciones, para los que se dispuso de más espacio, no solo dotándoles de anchura sino permitiendo un pequeño margen de separación espacial entre acera y carril-bici. Asimismo, al final del periodo de gobierno municipal se acometió la remodelación de ciertos "puntos de conflicto" existentes en el carril — tramos que propiciaban una grave confluencia física entre ciclistas y peatones debido a la escasez de espacio que inicialmente se permitió desde el área de Tráfico para el trazado del carril-bici-. Mientras que, como hemos visto, dicha limitación de espacio fue consecuencia de la pugna entre las dos esferas institucionales, las resoluciones finales de estos problemas, tras el auge del uso de la bicicleta, supusieron pequeños cambios en el trazado del carril, respetando por lo común los intereses ciclistas — si bien no siempre de forma óptima-y generalmente consistieron en reducir levemente la superficie de la calzada y destinarla al uso de peatones y ciclistas, concesión que hubiera sido im-

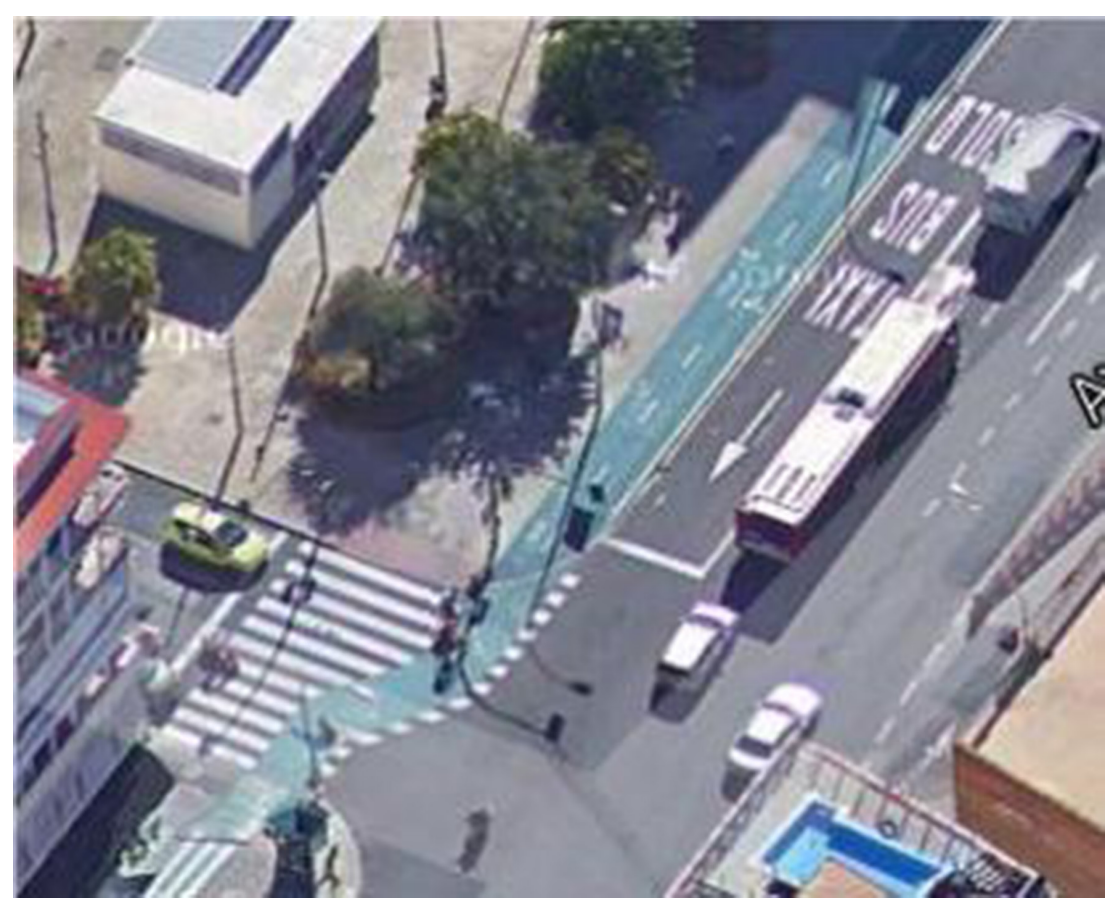
pensable en la primera fase de ejecución.

Ejemplos de ello son el emplazamiento de carril y acerado en un tramo de la calle José Laguillo (Figura 1), la circunvalación de la iglesia de San Hermenegildo en la calle Muñoz León (Figura 2) o la disposición de carril y acerado en la calle Demetrio de los Ríos en su confluencia con la avenida Menéndez Pelayo (Figura 3). Por su parte, la polémica local fue debilitándose al constatarse el éxito de las medidas implementadas y al instaurarse entre los ciudadanos el hábito de la presencia de la bicicleta. Los partidos políticos y medios de comunicación inicialmente hostiles reformularon sus argumentarios y estigmatizaron en menor medida a los ciclistas: en ello influyó, probablemente que, ante el volumen del conjunto de personas usuarias de bicicleta, comenzó a ser oportuno considerarles potenciales votantes, lectores y oyentes.
Figura 1. Carril-bici en calle José Laguillo. Fuente: Google Maps. Previamente el carril-bici transcurría contiguo al arbolado, sin permitir el tránsito de peatones. El nuevo trazado gana superficie a la calzada y destina el espacio que antes ocupaba el carril-bici al paso peatonal. El carril-bici retoma el eje previo mediante un trazado en curva junto al paso de peatones, lo que constituye una anomalía len el resto de la red, el carril-bici siempre cruza las calzadas en línea recta). Fuente: foto recuperada de Google Maps. 


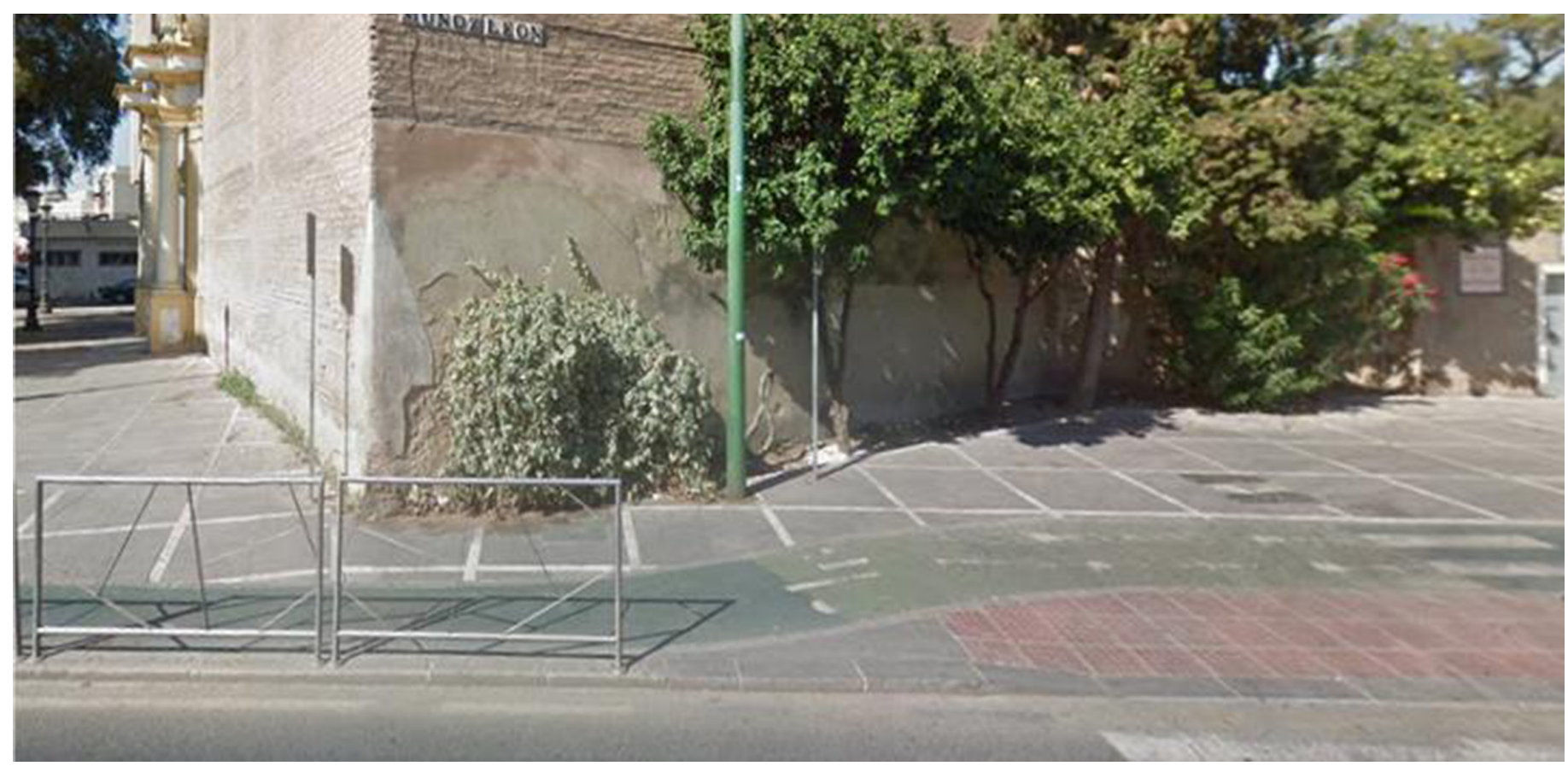

Figura 2. Carril-bici en calle Muñoz León. Previamente el acerado era mucho más estrecho y era ocupado en su totalidad por un angosto carril-bici que lindaba con la esquina sobresaliente del edificio, haciendo imposible el paso de un peatón y una bicicleta al mismo tiempo y propiciando posibles atropellos. El nuevo trazado gana espacio a la calzada, permitiendo un leve desvío del carril-bici y destinando al paso peatonal el espacio que antes ocupaba la vía ciclista. Para la resolución del problema, se mantuvo la angostura del carril-bici. Foto recuperada de Google Maps.
No hemos de obviar la repercusión del carril-bici sevillano: su impacto en el incremento de esta forma de movilidad en un corto espacio de tiempo atrajo el interés de técnicos municipales nacionales y extranjeros, equipos académicos que emprendieron nuevas investigaciones sobre el ciclismo urbano en Sevilla y periodistas españoles y extranjeros que cubrieron la noticia de la transformación experimentada en la ciudad. Todo ello repercutió en una mayor visibilidad nacional e internacional del "caso ciclista" sevillano y en un mayor fortalecimiento de la influencia del campo de ciclismo urbano local. La proyección internacional que Sevilla adquiría (cfr. Malpica, 2018) fortaleció aún más las posiciones de los intereses ciclistas en el debate entre instancias institucionales y en la opinión pública local, e incluso entidades que se habían alineado con los sectores opuestos a las nuevas infraestructuras sustituyeron sus críticas por las muestras públicas de satisfacción por los logros obtenidos, que incluso posteriormente llegaron a atribuirse ante organismos supranacionales. Aun así, algunos medios mantuvieron activa la polémica y sostuvieron su línea hostil hasta que la coalición entre el Partido Socialista Obrero Español e Izquierda Unida abandonó el gobierno municipal.

En consideración a los logros alcanzados en materia de ciclismo urbano, Sevilla fue elegida como sede para la celebración de eventos internacionales del sector, tales como el Congreso Ibérico de 2010 y la conferencia internacional Velo-City en 2011; en este último foro se dirige a los ministerios de transporte europeos la Carta de Sevilla, solicitándoles que contemplasen los beneficios de la movilidad ciclista. La aparición posterior de nuevos foros ciclistas europeos, en los que la presencia del asociacionismo ciclista sevillano supuso un reconocimiento al auge del uso de la bicicleta en la capital andaluza, posibilitó nuevas oportunidades de coordinación presencial de ámbito continental: así, con el establecimiento de la red Volunteers for Cycling Academy en 2011, auspiciada por el programa Lifelong Learning-Grundtvig Partnership de la Unión Europea, en la que A Contramano fue la única entidad española participante, se posibilitó una más frecuente y fructífera ocasión de coordinación y comunicación presencial entre asociaciones ciclistas de diversas ciudades europeas. 


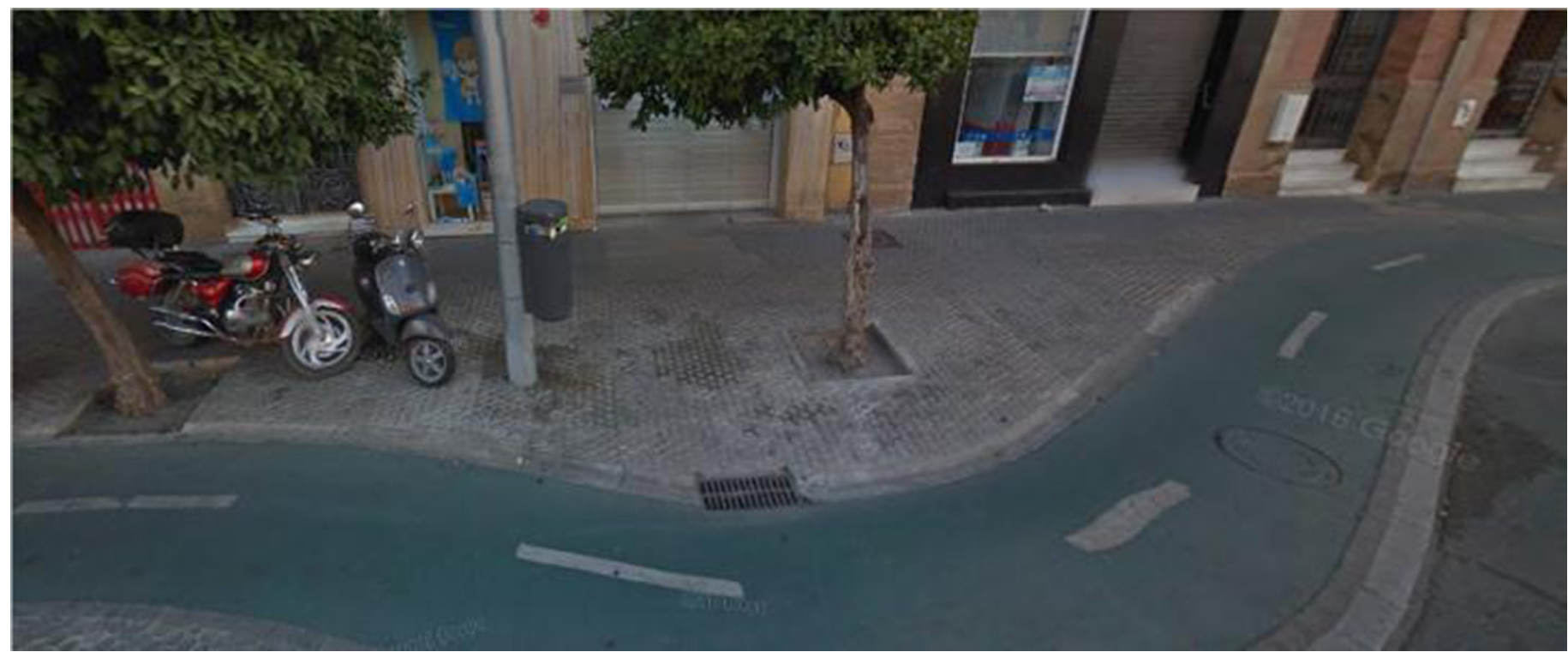

\section{Conclusiones y proyección del ciclismo urbano sevillano}

En la evolución de la experiencia sevillana, la asociación A Contramano, desde su contribución a generar una demanda social que acabó siendo asumida por el gobierno municipal, hasta su decisiva función en la ejecución de la respuesta a dicha demanda, mantuvo durante sus distintas fases la centralidad en el campo ciclista, que compartió con la esfera institucional entre los años 2003-2011 sin por ello renunciar a marcar el curso del proceso y a llevar adelante sus objetivos; al contrario, pareció expandir sus intereses al resto de organismos y entidades involucradas. Esta capacidad de liderazgo residió en diversos factores, entre los que ha de destacarse el capital acumulado en las posiciones que mantenían en el campo, su vínculo a las prácticas que constituían la razón de ser del mismo y la capacidad de penetración en las diversas entidades intervinientes en él, manteniendo un gran grado de autonomía a pesar de su interdependencia con las instituciones. La combinación de una experiencia personal ciclista de los miembros de A Contramano con la de su trayectoria activista y su bagaje técnico-científico supuso una miscelánea de saberes desde la que difundieron la necesidad de satisfacer una demanda social y a contribuir desde su conocimiento especializado a concretar el proyecto con el que se respondía a la misma. Su conocimiento específico sobre la movilidad ciclista les confirió una posición preeminente en la jerarquía simbólica ante el resto del campo: al conformarse como únicos expertos de la ciudad en este ámbito alcanzaron un gran capital simbólico hacia los demás componentes del campo y se convirtieron en "punto de paso obligado" manteniendo su autonomía. Su continuada interlocución y asesoría con las instituciones locales había permitido que se posicionaran a lo largo de la década anterior ante dichas entidades con las que terminarían confluyendo en el campo. Todo ello posibilitó su imbricación con el ámbito institucional sin que la asociación se marcara premeditadamente tal meta, sino más bien como resultado natural de los saberes y capital simbólico acopiados durante su trayectoria.

La capacidad de influencia que ello conlleva se incrementó también por la multiplicidad de posiciones que dichos agentes terminaron ocupando, abarcando espacios de interlocución pública y de toma de de-
Figura 3. Carril-bici en calle Demetrio de los Ríos en su confluencia con la Avenida Menéndez Pelayo. El carril-bici transcurría previamente entre el arbolado y la fachada, sin permitir adecuadamente el paso de peatones y propiciando conflictos entre viandantes y ciclistas. El nuevo trazado gana superficie a la calzada y destina el espacio que antes ocupaba el carril-bici al paso peatonal. El carril-bici se estrecha y mediante una curva se sitúa en el lado externo del arbolado. Foto recuperada de Google Maps. 
cisiones en las diversas áreas que terminaron conformando el campo, fueran estas de carácter asociativo, político, técnico, académico o comercial. Como activistas, además, tuvieron acceso al conocimiento de experiencias, teorías y consideraciones técnicas emanadas de la red internacional de asociaciones de ciclistas urbanos - red que trasciende el ámbito local y que supone el campo "general" del ciclismo urbano propiamente dicho- lo que propició una acumulación de dicho capital ante los demás agentes locales y legitimó aún más su prestigio y autoridad en el campo local.

En suma, la acumulación de capital simbólico guardaba relación con aspectos como la combinación de labores asociativas y de consultoría mantenida durante décadas, su saber específico en la materia, su integración en redes interterritoriales, su ubicuidad, y la función profesional de algunos de sus miembros. La oferta de lo que podemos considerar una nueva alternativa de movilidad - nueva en tanto que, aunque ya existiese la movilidad ciclista, esta se dota ahora de una circunstancia diferente, tanto física como simbólica, para su prácticano solo permite disponer de condiciones hasta entonces inéditas que generalicen su incorporación en los usos de amplios sectores sociales, sino que redefinen todo el espacio de alternativas de movilidad ya existentes y el significado social que estas poseían. El éxito de las nuevas infraestructuras ciclistas, más allá de acrecentar el capital simbólico del campo ciclista local, ha de interpretarse, en este sentido, como fruto de la sintonía entre, por un lado, las condiciones sociales y los intereses de estas posiciones de liderazgo dentro del campo y, por otra, las demandas, manifiestas o latentes, de diversas posiciones sociales que conforman la sociedad sevillana y que, en función de sus estructuras disposicionales y sus condiciones sociales, adoptan el ciclismo urbano como modo de locomoción y resignifican el resto de modalidades de transporte. La seguridad, la funcionalidad y la comodidad proporcionadas por la nueva infraestructura supusieron características que se adecuaron a las estructuras disposicionales de diversas posiciones sociales y que promovieron la adopción del ciclismo urbano por parte de perfiles muy heterogéneos; al mismo tiempo, otras ventajas aportadas por dicha infraestructura, tales como el ahorro, la autonomía o el vanguardismo, constituyen también características del nuevo producto ofertado desde el campo que facilitan aún más la incorporación al ciclismo urbano desde posiciones sociales específicas (cfr. Malpica, 2016).

Los integrantes del campo local ciclista acumularon tras el proceso más saberes de los que ostentaban al inicio del mismo: la evolución de los acontecimientos les situó ante la necesidad de afrontar y gestionar obstáculos e imprevistos de distinto tipo (desde idear políticas comunicacionales ante los ataques de ciertos medios de comunicación y diseñar el trazado de la vía ciclista en espacios concretos que entrañaban problemas de difícil resolución, hasta tomar decisiones sobre el tipo de colorante que debía aplicarse sobre el firme del carril-bici para obtener la adecuada rugosidad de la superficie o sobre el tipo de maquinaria con la que realizar el mantenimiento y limpieza de la nueva infraestructura) y, con ello, aumentaron su experiencia y conocimientos.

Sin embargo, ello no se tradujo en rentabilizar en todo su potencial esta acumulación de saberes. De la misma forma que no se aprovechó la proyección exterior que pudo tener "el caso de Sevilla" en materia de ciclismo urbano (cfr. Malpica, 2018), tampoco se realizó ninguna línea de actuación sistemática que contribuyera al posicionamiento y visibilización de los actores del campo como responsables de los logros 
alcanzados en un periodo en el que ninguna otra ciudad del sur de Europa había experimentado un éxito semejante. En palabras de uno de los miembros de A Contramano, entrevistado en pleno auge ciclista de la ciudad de Sevilla: "Tenemos que vender que somos los gurús de la única experiencia exitosa de ciclismo urbano de España, ¡de la única!”, en palabras de un entrevistado. No aprovechar el "capital humano" de los logros de Sevilla no solo comprometió la esperada apropiación de posiciones de influencia en el campo ciclista español o incluso internacional por parte de los miembros del campo, sino que limitó la propia influencia del campo local ciclista hacia actores externos y el referente del "caso de Sevilla" en su proyección exterior, así como la difusión de una experiencia que podrían aprovechar otras ciudades.

Otros muchos factores han contribuido al declive del ciclismo urbano sevillano durante la última década. El abandono de las políticas proactivas en favor del ciclismo urbano con la llegada del gobierno municipal del Partido Popular en 2011, el desmantelamiento ese mismo año tanto de la Comisión Cívica de la Bicicleta como de la Oficina de la Bicicleta, y la reubicación de su personal técnico en otras áreas de Urbanismo fueron factores que desinstitucionalizaron nuevamente el campo ciclista y debilitaron su influencia, si bien se mantuvo el capital simbólico acumulado durante el proceso, recayendo nuevamente la centralidad del campo en el ámbito asociativo. Las instituciones municipales, bajo dicho gobierno, aplicaron medidas que supusieron la tenue desactivación del fenómeno del ciclismo urbano, tales como la restricción del tráfico ciclista en algunas vías urbanas, y no implementaron medidas de calado en la expansión o mantenimiento de las infraestructuras (aunque esgrimieron los logros en materia de ciclismo del anterior gobierno municipal ante organismos europeos). Los posteriores gobiernos municipales del Partido Socialista Obrero Español, que rigen la ciudad desde 2015, han supuesto un cambio únicamente declaratorio: a pesar de su continua defensa pública de las bondades de la bicicleta, en líneas generales sus políticas se caracterizan de hecho por la misma inercia de abandono, cuando no de restricción, del ciclismo urbano. A falta de instituciones locales que formaran parte del campo, durante la última década las posiciones dotadas de mayor legitimidad institucional han sido ostentadas, principalmente, por el equipo académico del SIBUS y su notable labor de investigación y difusión, si bien la reciente limitación del mismo por parte de la Universidad de Sevilla, reduciéndolo a un mero servicio de préstamo de bicicletas, ha contribuido a una importante merma en el campo ciclista sevillano. En ausencia de un relanzamiento de las políticas pro-ciclistas y de una verdadera restitución de los órganos técnicos y de participación previamente existentes por parte del Ayuntamiento, se dificulta que la evolución del campo ciclista social sevillano conserve la influencia que ejerció durante su auge y amenaza con debilitar los logros asociados a ella. 


\section{Referencias bibliográficas}

A Contramano (2008). 21 años en defensa de una movilidad más sostenible. Sevilla: A Contramano- Asamblea Ciclista. Recuperado el 20 de julio de 2020 de: http://www.acontramano.org/antigua/noticias / memoria-web-1.pdf.

Bourdieu, Pierre (1993). Deporte y clase social. En Barbero, José Ignacio (ed.), Materiales de sociología del deporte (pp. 57-82). Madrid: Ediciones de la Piqueta.

Bourdieu, Pierre (1998). La distinción: criterios y bases sociales del gusto. Madrid: Taurus.

Castells, Manuel (1986). La ciudad y las masas: sociología de los movimientos sociales urbanos. Madrid: Alianza Editorial.

Castells, Manuel (1988). La cuestión urbana. Madrid: Siglo XXI.

Gottdiener, Mark; \& Hutchison, Ray (2011). The New Urban Sociology. Boulder: Westview Press.

Lefebvre, Henri (1978). El derecho a la ciudad. Barcelona: Península.

Lefebvre, Henri (1983). La revolución urbana. Madrid: Alianza Editorial.
Malpica, Pedro (2016). Discursos sobre la bicicleta según posiciones sociales. En Hernández, Macarena. (coord.), Bicitopías. Hacia una antropología de la movilidad urbana (pp. 97-113). Barcelona: Icaria.

Malpica, Pedro (2017). La movilidad ciclista en la transición a un nuevo modelo de ciudad: el caso de Sevilla (Tesis doctoral). Universidad de Sevilla, Sevilla.

Malpica, Pedro (2018). La (incompleta) proyección de Sevilla como "Ciudad Ciclista”. En Calahorro Lizondo, Belén; \& Ortega Botella, Diego (dirs.), XV Congreso Ibérico "La Bicicleta y la Ciudad". Congreso organizado por ConBici y FPCUB. Valencia, España.

Marqués, Ricardo (2011). Sevilla: una experiencia exitosa de promoción de la movilidad en bicicleta en el Sur de Europa. Hábitat y Sociedad, 3, 107-130. DOI: 10.12795/HabitatySociedad.2011.i3.07

Martín Criado, Enrique (2008). El concepto de campo como herramienta metodológica. REIS: Revista Española de Investigaciones Sociológicas, 123, 11-33. DOI: $10.2307 / 40184891$

Malpica, Pedro (2020). La influencia del campo social pro-bicicleta en el proceso de promoción del ciclismo urbano en Sevilla. Hábitat y Sociedad, 13, 151-168.

<http://dx.doi.org/10.12795/HabitatySociedad.2020.i13.09> 